\title{
Effect of dietary supplementation of Bacillus subtilis B10 on biochemical and molecular parameters in the serum and liver of high-fat diet-induced obese mice ${ }^{* \#}$
}

\author{
Kai LEI $I^{\S}$, Ya-li LI ${ }^{\S}$, Yang WANG, Jing WEN, Hong-zhao WU, Dong-you YU, Wei-fen LI $I^{\dagger \sharp}$ \\ (Key Laboratory of Molecular Animal Nutrition of the Ministry of Education, Institute of Feed Science, \\ College of Animal Sciences, Zhejiang University, Hangzhou 310058, China) \\ †E-mail: wfli@zju.edu.cn
}

Received Dec. 1, 2014; Revision accepted May 21, 2015; Crosschecked May 25, 2015

\begin{abstract}
While a high-fat diet (HFD) is assumed to be related to fat-mediated oxidative stress decreasing antioxidant enzyme activity, probiotics are believed to have positive effects on the regulation of HFD-induced obesity as well as lipid metabolism, energy homeostasis, and anti-oxidation. Because Bacillus subtilis B10 has beneficial effects on the abnormal lipid metabolism and the oxidative stress in HFD-induced obese mice, ICR mice were randomly assigned into an HFD group and the HFD was supplemented with $0.1 \%$ (w/w) Bacillus subtilis B10 (HFD+B10 group). Thereafter, 30-d treatments were run, and then hepatic lipid level and antioxidant status were measured. The expression of genes related to lipid metabolism and oxidative stress in the liver was determined by reverse-transcription quantitative polymerase chain reaction (RT-qPCR). We found that HFD-induced obese mice treated with B10 showed a decrease in weight gain, serum glucose activity as well as hepatic triglyceride (TG), glutamic oxaloacetic transaminase (GOT), and glutamic pyruvic transaminase (GPT) activities. In addition, the gene expressions of antioxidant genes, glutathione reductase $(G R)$, xanthine oxidase $(X O)$, heat-shock protein $90(H s p 90)$, and lipid synthesis gene $3 \beta$-hydroxysteroid- $\triangle 24$ reductase (DHCR24) in the HFD+B10 group were down-regulated, suggesting alleviation of oxidative stress, while the lipolysis gene 3-hydroxy-3-methylglutaryl-CoA synthase 2 (HMGCS2), energy metabolism gene peroxisome proliferator-activated receptor $\alpha(P P A R \alpha)$ and the gene encoding tumor-suppressor protein $p 53$ were up-regulated. The regulatory and positive effect of dietary supplementation of probiotic B10 suggests that it has a beneficial effect on the homeostasis of the lipid metabolism and on alleviating oxidative stress in HFD-induced obese mice.
\end{abstract}

Key words: Bacillus subtilis, High-fat diet, Oxidative stress, Lipid metabolism doi:10.1631/jzus.B1400342 Document code: A

CLC number: S816.3

\section{Introduction}

${ }^{\ddagger}$ Corresponding author

$\S$ The two authors contributed equally to this work

* Project supported by the National High-Tech R \& D Program (863) of China (No. 2013AA102803D), the National Natural Science Foundation of China (No. 31472128), and the Major Science and Technology Project of Zhejiang Province (No. 2006C12086), China

\# Electronic supplementary materials: The online version of this article (http://dx.doi.org/10.1631/jzus.B1400342) contains supplementary materials, which are available to authorized users

(D) ORCID: Wei-fen LI, http://orcid.org/0000-0001-8159-9876

(C) Zhejiang University and Springer-Verlag Berlin Heidelberg 2015
Obesity has been recognized as a major underlying factor in the pathogenesis of several diseases, including metabolic syndrome, insulin resistance, type 2 diabetes, hypertension, dyslipidemia, atherosclerosis, and several forms of cancer. It has become a serious public health problem both in industrialized countries and developing countries (Matsuda and Shimomura, 2013). As well as congenital genetics, obesity is also caused by acquired environmental 
factors (Tsai et al., 2014), especially high fat intake (Rizvi et al., 2003). Many reports have demonstrated that obesity is linked to an obvious oxidative stress (Furukawa et al., 2004; Matsuzawa-Nagata et al., 2008). Charradi et al. (2013) found that obesity is strongly related to systemic oxidative stress and was in particular concerned with the relationship between altered glutathione homeostasis and organ lipotoxicity associated with diet-induced obesity. Moreover, antioxidant supplementation showed beneficial effects in preventing dyslipidemia disease caused by a high-fat diet (HFD) (Gorinstein et al., 2006). Oxidative stress is an imbalance between oxidants and antioxidants (Sies, 1997). It can result in DNA hydroxylation, protein denaturation, lipid per-oxidation, apoptosis, tissue damage (Valko et al., 2006), and a disruption in the redox signaling pathway (Kamata and Hirata, 1999).

Several strategies have been used to prevent obesity, including diet control, exercise, behavior therapy and medication. Probiotics, which are defined as "live microorganisms that, when administrated in adequate amounts, confer a health benefit on the host" (Araya et al., 2002), could modulate the intestinal flora and have some anti-oxidative and lipid-lowering abilities (Endo et al., 2013; Everard et al., 2014). Bacillus subtilis is an intestinal microorganism that may grow in the gut and consume oxygen to maintain an anaerobic environment for the prevention or therapy of gastrointestinal disorders (Hu et al., 2014). In addition, Bacillus subtilis is preferred due to its higher resistance to harsh environments and capacity for long-term storage at ambient temperature (Hong et al., 2005). Previously, we have reported that $\mathrm{Ba}$ cillus subtilis B10 possessed positive effects on the anti-oxidative defense of cells in vitro (Li et al., 2013) and those findings lead us to further investigate the regulatory effect of Bacillus subtilis $\mathrm{B} 10$ on the antioxidative and lipid-lowering capacities of HFDinduced obese mice.

\section{Materials and methods}

\subsection{Bacterial strain}

Bacillus subtilis $\mathrm{B} 10$ powder $\left(10^{8}\right.$ colony-forming unit $(\mathrm{CFU}) / \mathrm{g})$ was prepared by Microbiology and
Genetic Engineering Laboratory, Institute of Feed Sciences, Zhejiang University, China. B10 strain was cultured on Luria-Bertani media, kept at $37{ }^{\circ} \mathrm{C}$ for $24 \mathrm{~h}$ and shaken at $180 \mathrm{r} / \mathrm{min}$. Pure bacterial cells were collected after centrifugation at $5000 \mathrm{~g}$ for $10 \mathrm{~min}$ at $4{ }^{\circ} \mathrm{C}$ and cooling. Thereafter, these cells were washed twice with sterile $0.85 \%(8.5 \mathrm{~g} / \mathrm{L})$ sodium chloride solution. Ultimately, the culture purity and identification were constantly checked by the spreading plate method (Nikoskelainen et al., 2003).

\subsection{Animals and diets}

Thirty male ICR mice (7- 8 weeks old, $n=15$ per group) were obtained from the Institutional Animal Care and Use Committee of Zhejiang University, China. All mice were housed in standard plastic cages (three mice per cage) and maintained under a 12-h light-dark cycle at constant temperature and humidity $\left((23 \pm 1){ }^{\circ} \mathrm{C}\right.$ and $(55 \pm 5) \%$, respectively). One group of mice was fed with an HFD $(92.8 \%$ normal diet, $2 \%$ cholesterol, $5 \%$ lard, and $0.2 \%$ cholate) and the other was kept on an HFD supplemented with $0.1 \%(\mathrm{w} / \mathrm{w})$ $\mathrm{B} 10$ powder for $30 \mathrm{~d}$. The normal diet was provided by Shanghai SLAC Laboratory Animal Co., Ltd. (Shanghai, China) and its nutrient components level is listed in a supplemental material Table S1. During the preparation of the B10 powder, starch was used to dilute B10 and the same amount of starch was also added to the HFD group to compensate for the difference in nutrient composition of the diets. All the mice were fed ad libitum and food intake was recorded. The experiment was approved by and performed in accordance with the guidelines of the local ethics committee.

\subsection{Sample collection}

After $30 \mathrm{~d}$, mice $(n=6)$ from each group (HFD and B10) fasted for $12 \mathrm{~h}$, and then were anesthetized with diethyl ether. Mice were killed by cervical dislocation and the blood samples were taken from the inferior vena cava. After incubation at $4{ }^{\circ} \mathrm{C}$ for $30 \mathrm{~min}$ and centrifugation at $2000 \mathrm{~g}$ for $20 \mathrm{~min}$, the serum was obtained (Centrifuge 5804R, Eppendorf, Germany). Liver samples were dissected out and placed in liquid nitrogen. Samples were finally frozen and kept at $-80{ }^{\circ} \mathrm{C}$ for no more than 2 months until further analysis. 


\subsection{Biochemical assays of serum}

The contents of glucose, triglyceride (TG), total cholesterol (TC), low-density lipoprotein cholesterol (LDL-C), high-density lipoprotein cholesterol (HDL-C), blood urea nitrogen (BUN), glutamic oxaloacetic transaminase (GOT), and glutamic pyruvic transaminase (GPT) in serum were determined by spectrophotometry according to the kit manufacturer's instructions. The methods of those kits are presented in the supplemental material Data S1. The materials of glucose measurement were purchased from Rongsheng Bio-pharmaceutical Co., Ltd., Shanghai, China. Kits for serum TG and TC were purchased from Saike Bio-technology Co., Ltd., Ningbo, China. Kits for serum BUN, GOT, and GPT were bought from Nanjing Jiancheng Bioengineering Institute, Nanjing, China. Materials for serum LDL-C and HDL-C were purchased from Beihuakangtai Clinical Reagent Co., Beijing, China.

\subsection{Biochemical assays of the liver}

Liver samples were homogenized with ice-cold physiologic saline $(1: 10, \mathrm{v} / \mathrm{v})$ and centrifuged at $2000 \mathrm{~g}$ for 10 min (Centrifuge 5804R, Eppendorf, Germany). Supernatant was collected for determination of the total anti-oxidant capability (T-AOC), anti-superoxide anion activity (ASOA), concentrations of TC, TG, LDL-C, HDL-C, 8-hydroxy-2'-deoxyguanosine (8$\mathrm{OHdG})$, glutathione (GSH), and thioredoxin reductase (TrxR), and the activities of superoxide dismutase (SOD), catalase (CAT), glutathione peroxidase (GSH-Px), and xanthine oxidase (XO). Kits for hepatic TC and TG were obtained from Saike Biological Technology Co., Ltd., Ningbo, China. Kits for hepatic LDL-C and HDL-C were purchased from Beihuakangtai Clinical Reagent Co., Beijing, China. Kits for SOD, CAT, GSH-Px, XO, T-AOC, ASOA, and GSH were purchased from Nanjing Jiancheng Bioengineering Institute, Nanjing, China. All the above parameters were determined by spectrophotometry according to the manufacturers' instructions. Enzyme-linked immunosorbent assay (ELISA) kits for 8-OHdG and TrxR were purchased from Bioleaf Biological Co., Ltd., Shanghai, China.

\subsection{RNA extraction and quantitative real-time polymerase chain reaction (PCR)}

Liver tissues of approximately $100 \mathrm{mg}$ were used for RNA extraction. RNA was extracted using the RNAiso plus method (TaKaRa, Dalian, China) according to the instructions of the manufacturer. Quantitative and qualitative analyses of isolated RNA were assessed from the ratio of absorbance at 260 and $280 \mathrm{~nm}$ by NanoDrop spectrophotometer (Thermo Scientific, Wilmington, DE, USA) and agarose gel electrophoresis (Sangon Biotech, Shanghai, China). Complementary DNA (cDNA) was synthesized from $1 \mu \mathrm{g}$ of total RNA using M-MLV reverse transcriptase (TaKaRa, Dalian, China). Transcriptional changes were then identified by quantitative PCR (qPCR), which was performed using the Premix Ex Taq ${ }^{\mathrm{TM}}$ with SYBR Green (TaKaRa, Dalian, China) as per the manufacturer's instructions, and the ABI 7500 Fast Real-Time PCR system (Applied Biosystems, Carlsbad, CA, USA). The thermocycle protocol lasted for $30 \mathrm{~s}$

Table 1 Primers used for real-time PCR

\begin{tabular}{|c|c|}
\hline Gene & Primer sequence \\
\hline \multirow[t]{2}{*}{$G A P D H$} & F: 5'-GTTGTCTCCTGCGACTTCA-3' \\
\hline & R: 5'-GCCCCTCCTGTTATTATGG-3' \\
\hline \multirow[t]{2}{*}{$\beta$-actin } & F: 5'-CCTGTACGCCAACACAGTGC-3' \\
\hline & R: 5'-ATACTCCTGCTTGCTGATCC-3' \\
\hline \multirow[t]{2}{*}{ Hsp90 } & F: 5'-CAAGAGGTTGATAGAGCGTTT-3' \\
\hline & R: 5'-TTGTTCTCGGGACTTTGGA-3' \\
\hline \multirow[t]{2}{*}{ CAT I } & F: 5'-GGCATCCTAACCTCCAACCA-3' \\
\hline & R: 5'-TGCTCATACACCATCCCACA-3' \\
\hline \multirow[t]{2}{*}{$P P A R \alpha$} & F: 5'-CTTTACATCAGTGTTTCCGTCAG-3' \\
\hline & R: 5'-TCAAATTGCCACCGTTCTT-3' \\
\hline \multirow[t]{2}{*}{$P P A R \beta$} & F: 5'-GGTGACCCTCCTCAAGTATGG-3' \\
\hline & R: 5'-GGTGTCCTGGATGGCTTCTA-3' \\
\hline \multirow[t]{2}{*}{$P P A R \gamma$} & F: 5'-AGAACCTGCATCTCCACCTTA-3' \\
\hline & R: 5'-CCACAGACTCGGCACTCAAT-3' \\
\hline \multirow[t]{2}{*}{ DHCR24 } & F: 5'-TACAAGAAGACCCATAAGAACATC-3' \\
\hline & R: 5'-CCACAGACTCGGCACTCAAT-3' \\
\hline \multirow[t]{2}{*}{$H M G C S 2$} & F: 5'-GGACCGTGCTCCCTTCTTAG-3' \\
\hline & R: 5'-GAGCTCTTCGTGGGTTCTGT-3' \\
\hline \multirow[t]{2}{*}{$T R X 2$} & F: 5'-GGAAACCAGAAGCCGAACA-3' \\
\hline & R: 5'-GACAAGGAATAGAAGGGACAGAT-3' \\
\hline \multirow[t]{2}{*}{$G R$} & F: 5'-GTAGGAAGCCCACCACGAC-3' \\
\hline & R: 5'-AGCATAGACGCCTTTGACATT-3' \\
\hline \multirow[t]{2}{*}{$X O$} & F: 5'-CTGTCTTTGCGAAGGATGAG-3' \\
\hline & R: 5'-CTGGATTGTGATAATGGCTGG-3' \\
\hline \multirow[t]{2}{*}{$S O D$} & F: 5'-GAAGCATGGCGATGAAAGC-3' \\
\hline & R: 5'-CAGTCACATTGCCCAGGTCTC-3' \\
\hline \multirow[t]{2}{*}{ GST } & F: 5'-GCCCTGTGGCATAAGGTGAT-3' \\
\hline & R: 5'-TTTGTCCTGGAGGAACTTGTCT-3' \\
\hline \multirow[t]{2}{*}{$G C S$} & F: 5'-AACTCTGCCTATGTGGTATTCG-3' \\
\hline & R: 5'-TTCCCATTGATGATGGTGTCTA-3' \\
\hline
\end{tabular}

GAPDH: glyceraldehyde-3-phosphate dehydrogenase; Hsp 90 : heatshock protein 90; CAT I: carnitine acyltransferase I; PPAR : peroxisome proliferator-activated receptor $\alpha$; PPAR $\beta$ : peroxisome proliferatoractivated receptor $\beta$; PPAR $\gamma$ : peroxisome proliferator-activated receptor $\gamma$; DHCR 24: lipid synthesis gene $3 \beta$-hydroxysteroid- $\Delta 24$ reductase; $H M G C S 2$ : 3-hydroxy-3-methylglutaryl-CoA synthase 2; $T R X 2$ : thioredoxin reductase 2; GR: glutathione reductase; $X O$ : xanthine oxidase; SOD: superoxide dismutase; GST: glutathione $S$-transferase; GCS: glutamylcysteine synthetase; F: forward; R: reverse 
at $95^{\circ} \mathrm{C}$, followed by 40 cycles of $5 \mathrm{~s}$ denaturation at $95^{\circ} \mathrm{C}, 34 \mathrm{~s}$ annealing/extension at $60{ }^{\circ} \mathrm{C}$, and then a final melting curve analysis to monitor purity of the PCR product. Primer sequences for the mouse genes were designed and selected by Primer 5.0 and Oligo 7.0 softwares and the sequences are presented in Table 1. The $2^{-\Delta \Delta C_{\mathrm{q}}}$ method was used to estimate mRNA abundance. $\Delta C_{\mathrm{q}}$ is $C_{\mathrm{q}}$, target $-C_{\mathrm{q}}$, reference and $\Delta \Delta C_{\mathrm{q}}$ is $\Delta C_{\mathrm{q} \text {, treatment }}-\Delta C_{\mathrm{q} \text {, control. }}$. Relative gene expression levels were normalized to those of the eukaryotic reference genes glyceraldehyde-3-phosphate dehydrogenase $(G A P D H)$ and $\beta$-actin .

\subsection{Statistical analysis}

Data are expressed as mean \pm standard deviation (SD) and were analyzed using the one-way analysis of variance (ANOVA) procedure of SPSS 16.0 (SPSS Inc., Chicago, IL, USA) for Windows by the Tukey test and the variable used is the administration of B10. Differences were considered statistically significant at $P<0.05$.

\section{Results}

\subsection{Effects of dietary supplementation of Bacillus} subtilis B10 on body weight and food intake of mice

While the final body weight and average daily weight gain for HFD+B10 group significantly $(P<0.05)$ decreased compared with the HFD group, no significant differences in daily food intake were observed between the two groups (Table 2).

\subsection{Effects of dietary supplementation of Bacillus subtilis B10 on lipid profile in the serum and liver} of mice

Hepatic TC and TG of HFD-fed mice were effectively $(P<0.05)$ decreased in B10-treated mice. In addition, the TC, LDL-C, and HDL-C levels in serum of the B10 treatment group were significantly $(P<0.05)$ increased (Table 3). Besides, B10 supplementation also exhibited a significant decrease in the serum glucose concentration and GOT and GPT activities compared with the HFD group, while serum BUN was unaffected between the two groups (Table 4).

\subsection{Effects of dietary supplementation of Bacillus subtilis B10 on mice hepatic mRNA expression of genes associated with lipid metabolism of mice}

The administration of B10 down-regulated the transcript levels of $3 \beta$-hydroxysteroid- $\Delta 24$ reductase $(D H C R 24)$ significantly $(P<0.05)$ and up-regulated that of peroxisome proliferator-activated receptor $\alpha$ $(P P A R \alpha)$ and 3-hydroxy-3-methylglutaryl-CoA synthase 2 (HMGCS2) remarkably $(P<0.05)$. No significant differences were noted in the gene expression levels of carnitine acyltransferase I (CAT I), peroxisome proliferator-activated receptor $\beta(P P A R \beta)$, and peroxisome proliferator-activated receptor $\gamma(P P A R \gamma)$ between the two groups (Fig. 1).

Table 2 Effects of dietary supplementation of Bacillus subtilis B10 on body weight and food intake of mice

\begin{tabular}{ccccc}
\hline Group & Initial body weight $(\mathrm{g})$ & Final body weight $(\mathrm{g})$ & Average daily gain $(\mathrm{g})$ & Average food intake $(\mathrm{g})$ \\
\hline HFD & $35.47 \pm 0.58$ & $41.16 \pm 0.52^{\mathrm{a}}$ & $0.19 \pm 0.03^{\mathrm{a}}$ & $4.72 \pm 0.30$ \\
HFD+B10 & $35.13 \pm 1.20$ & $38.51 \pm 1.10^{\mathrm{b}}$ & $0.11 \pm 0.03^{\mathrm{b}}$ & $5.02 \pm 0.30$ \\
\hline
\end{tabular}

Data are expressed as mean \pm SD ( $n=15$ for initial body weight, final body weight, and average daily gain; $n=5$ for average food intake). Different letters indicate a statistically significant difference between groups $(P<0.05)$

Table 3 Effects of dietary supplementation of Bacillus subtilis B10 on lipid profiles in the liver and serum of mice

\begin{tabular}{|c|c|c|c|c|c|c|}
\hline \multirow{2}{*}{ Group } & \multicolumn{4}{|c|}{ Serum } & \multicolumn{2}{|c|}{ Liver } \\
\hline & $\mathrm{TG}(\mathrm{mmol} / \mathrm{L})$ & $\mathrm{TC}(\mathrm{mmol} / \mathrm{L})$ & LDL-C $(\mathrm{mmol} / \mathrm{L})$ & HDL-C (mmol/L) & $\mathrm{TG}(\mathrm{mg} / \mathrm{g})$ & $\mathrm{TC}(\mathrm{mg} / \mathrm{g})$ \\
\hline HFD & $0.96 \pm 0.09$ & $3.14 \pm 0.12^{\mathrm{b}}$ & $0.32 \pm 0.08^{\mathrm{b}}$ & $1.63 \pm 0.11^{\mathrm{b}}$ & $20.35 \pm 1.38^{\mathrm{a}}$ & $6.72 \pm 0.63^{\mathrm{a}}$ \\
\hline $\mathrm{HFD}+\mathrm{B} 10$ & $0.94 \pm 0.08$ & $4.06 \pm 0.17^{\mathrm{a}}$ & $0.55 \pm 0.11^{\mathrm{a}}$ & $2.41 \pm 0.58^{\mathrm{a}}$ & $13.60 \pm 0.60^{\mathrm{b}}$ & $4.66 \pm 0.17^{\mathrm{b}}$ \\
\hline
\end{tabular}

Data are expressed as mean $\pm \mathrm{SD}(n=6)$. Different letters indicate a statistically significant difference between groups $(P<0.05)$

Table 4 Effects of dietary supplementation of Bacillus subtilis B10 on serum biochemical parameters of mice

\begin{tabular}{ccccc}
\hline Group & Glucose $(\mathrm{mmol} / \mathrm{L})$ & BUN $(\mathrm{mmol} / \mathrm{L})$ & GOT $(\mathrm{IU} / \mathrm{L})$ & GPT $(\mathrm{IU} / \mathrm{L})$ \\
\hline HFD & $8.62 \pm 1.00^{\mathrm{a}}$ & $5.30 \pm 0.39$ & $4.43 \pm 0.28^{\mathrm{a}}$ & $5.68 \pm 0.30^{\mathrm{a}}$ \\
HFD+B10 & $5.18 \pm 0.54^{\mathrm{b}}$ & $5.28 \pm 0.22$ & $3.30 \pm 0.10^{\mathrm{b}}$ & $3.12 \pm 0.38^{\mathrm{b}}$ \\
\hline
\end{tabular}

Data are expressed as mean $\pm \mathrm{SD}(n=6)$. Different letters indicate a statistically significant difference between groups $(P<0.05)$ 

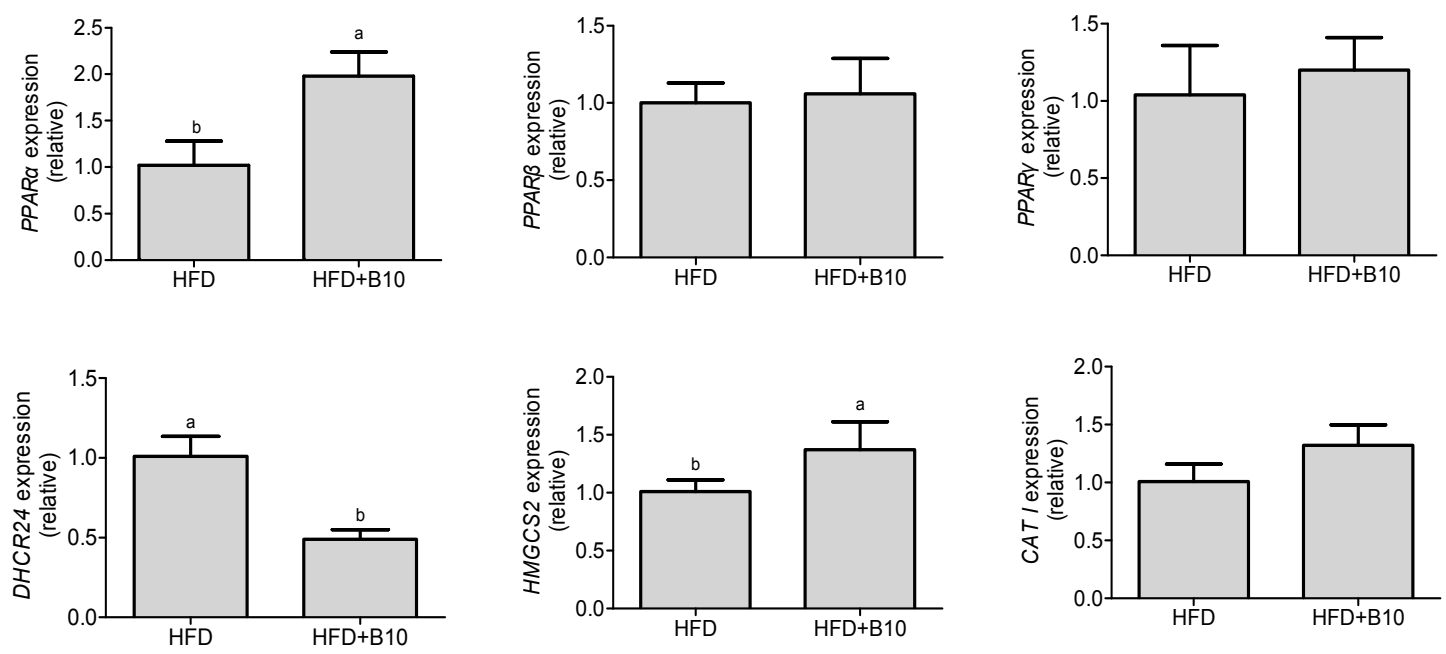

Fig. 1 Effect of dietary supplementation of Bacillus subtilis B10 on the expression of mRNA associated with lipid metabolism in mice liver of the HFD (high-fat diet) and HFD+B10 (high-fat diet with $0.1 \%$ Bacillus subtilis B10) groups

All mRNA quantification data are normalized to the reference gene. Gene expression levels are expressed as values relative to that of the HFD group. Data are expressed as mean \pm SD $(n=6)$. Different letters indicate a statistically significant difference between groups $(P<0.05)$

Table 5 Effects of dietary supplementation of Bacillus subtilis B10 on HFD-induced oxidative stress in the liver of mice

\begin{tabular}{cccccccccc}
\hline \multirow{2}{*}{ Group } & $\begin{array}{c}\text { T-AOC } \\
(\mathrm{U} / \mathrm{mg} \text { prot })\end{array}$ & $\begin{array}{c}\text { TrxR } \\
(\mathrm{mg} / \mathrm{L})\end{array}$ & $\begin{array}{c}\text { SOD } \\
(\mathrm{U} / \mathrm{mg} \text { prot })\end{array}$ & $\begin{array}{c}\text { CAT } \\
(\mathrm{U} / \mathrm{mg} \text { prot })\end{array}$ & $\begin{array}{c}\text { GSH-Px } \\
(\mathrm{U} / \mathrm{mg} \text { prot })\end{array}$ & $\begin{array}{c}\text { GSH } \\
(\mathrm{mg} / \mathrm{g} \text { prot})\end{array}$ & $\begin{array}{c}\text { ASOA } \\
(\mathrm{U} / \mathrm{g} \text { prot})\end{array}$ & $\begin{array}{c}\text { XO } \\
(\mathrm{U} / \mathrm{g} \text { prot})\end{array}$ & $\begin{array}{c}8-\mathrm{OHdG} \\
(\mathrm{pg} / \mathrm{ml})\end{array}$ \\
\hline HFD & $0.84 \pm 0.04$ & $0.96 \pm 0.04$ & $55.32 \pm 4.00$ & $0.83 \pm 0.06$ & $597.15 \pm 31.74^{\mathrm{c}}$ & $0.81 \pm 0.12$ & $82.18 \pm 4.53$ & $16.00 \pm 1.26$ & $14.42 \pm 1.32^{\mathrm{a}}$ \\
HFD+B10 & $1.04 \pm 0.17$ & $1.31 \pm 0.13$ & $50.53 \pm 4.37$ & $1.15 \pm 0.13$ & $1441.22 \pm 105.98^{\mathrm{a}}$ & $0.90 \pm 0.08$ & $75.82 \pm 4.07$ & $14.45 \pm 0.76$ & $10.28 \pm 1.02^{\mathrm{b}}$ \\
\hline
\end{tabular}

Data are expressed as mean $\pm \mathrm{SD}(n=6)$. Different letters indicate a statistically significant difference between groups $(P<0.05)$. prot: protein

\subsection{Effects of dietary supplementation of Bacillus subtilis B10 on hepatic antioxidant biochemical values and DNA damage of mice}

As shown in Table 5, the administration of B10 lowered concentrations of hepatic 8-OHdG remarkably $(P<0.05)$, increased T-AOC, GSH, and TrxR levels and the CAT activity slightly, and significantly elevated, by a factor of 1.4, the GSH-Px activity $(P<0.05)$.

\subsection{Effects of dietary supplementation of Bacillus} subtilis B10 on hepatic mRNA expression of genes associated with oxidative stress of mice

It was found that the transcript levels of $G R, X O$ and $H s p 90$ genes in the liver were much less for the B10 group than for the HFD group $(P<0.05)$. However, an increased hepatic gene expression of $p 53$ was also observed in the $\mathrm{B} 10$ treatment group $(P<0.05)$. There was no significant difference between the two groups in the transcript levels of $S O D$, glutamylcysteine synthetase $(G C S)$, and thioredoxin reductase 2 (TRX2) (Fig. 2).

\section{Discussion}

A 30-d supplementation of B10 is able to decrease mice body weight, although there is no difference in food intake between the two groups (Table 2). The decrease in body weight induced by probiotics is in agreement with the results of other research (Park et al., 2013; Wang et al., 2015). Although we did not compare the digestive capacity and nutrient absorption of mice between the HFD and HFD+B10 groups, previous research showed that the digestive enzyme activity was unchanged between animals fed an HFD or HFD supplemented with probiotics (An et al., 2011). So we conjecture that the lower body weight gain caused by B10 was due to its modulation of lipid metabolism other than because of 

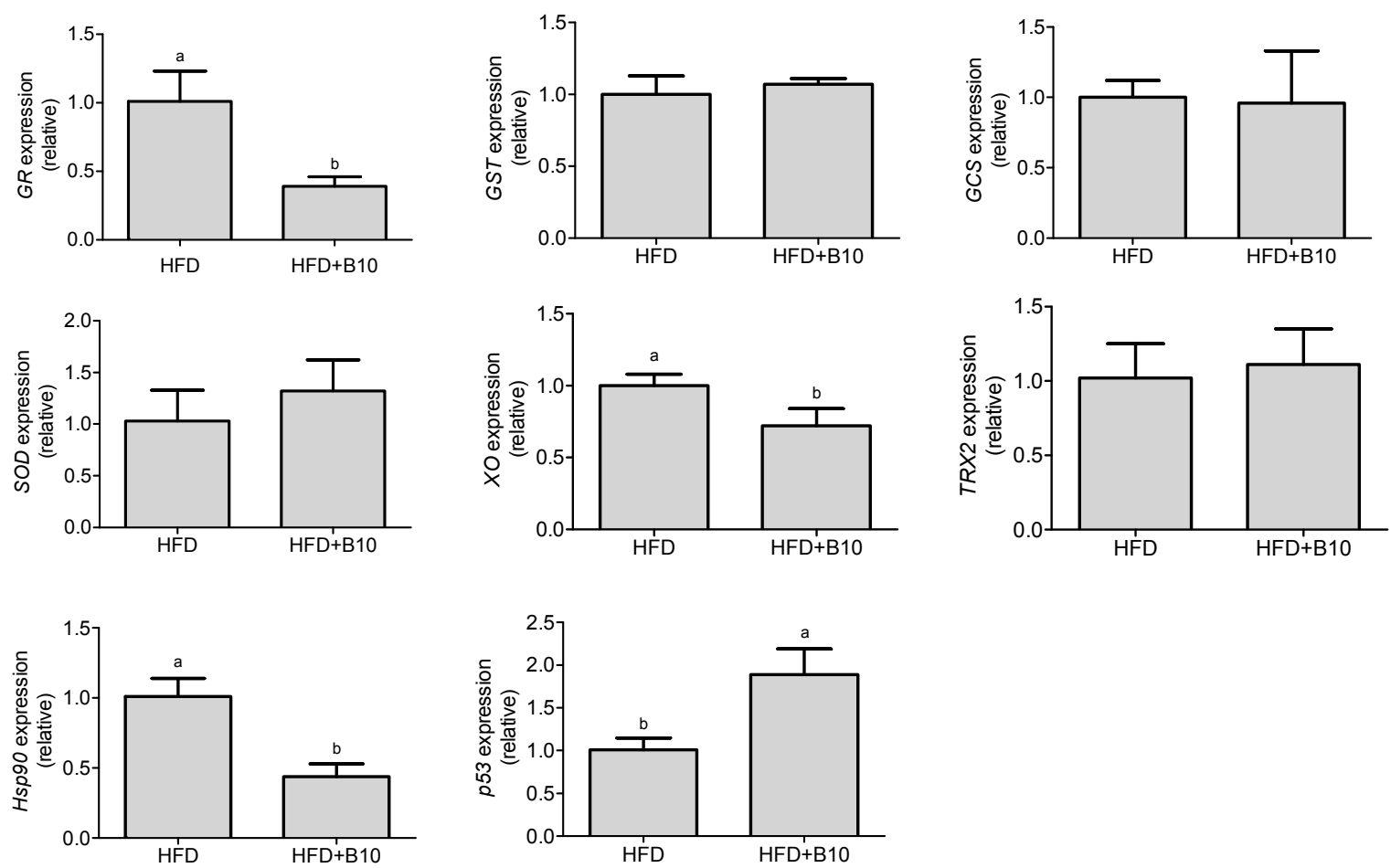

Fig. 2 Effect of dietary supplementation of Bacillus subtilis B10 on the expression of mRNA associated with antioxidation in mice liver of the HFD (high-fat diet) and HFD+B10 (high-fat diet with $0.1 \%$ Bacillus subtilis B10) groups

All mRNA quantification data are normalized to the reference gene. Gene expression levels are expressed as values relative to that of the HFD group. Data are expressed as mean \pm SD $(n=6)$. Different letters indicate a statistically significant difference between groups $(P<0.05)$

different food intake or digestion. In recent years, numerous investigations have shown that probiotics can be considered as biotherapeutics in treating abnormal lipid metabolism (Park et al., 2013; Xin et al., 2014). In our study, hepatic TC, TG and serum HDL-C, glucose, activities of GOT and GPT are much less than those of HFD-fed mice (Tables 3 and 4). In fact, GPT is an enzyme related to the liver fat accumulation (Westerbacka et al., 2004). From the point of view of Eckel et al. (2005), once fatty liver disease occurs, widespread lipid will accumulate in muscles and other organs, which facilitates the metabolic syndrome. As GPT could be a sensitive marker of hepatic dysfunction associated with metabolic syndrome, even in the range below the current limit (Jeong et al., 2004), the low GPT activity in the B10 treatment group may imply that B10 could be involved in the alleviation of the susceptibility to metabolic syndrome in HFD-fed mice. Nevertheless, the significant increases of TC and LDL-C in the serum were in contrast to the findings of Panda et al. (2006), in which serum TC and LDL were reduced by dietary supplementation of Lactobacillus sporogenes. However, the study of Novak et al. (2011) also found an enhanced serum LDL-C level. In their opinion, the lowered concentrations of cecal propionic and butyric acids in Bacillus-fed chickens might be the reason for higher levels of LDL compared with the control, because products of bacterial fermentation, specifically short chain fatty acids, may inhibit cholesterol synthesis in the plasma cholesterol in the liver (Rafter, 2002).

Genes of lipid synthesis (PPAR $\gamma$, DHCR24, $P P A R \beta)$, lipolysis (HMGCS2, CAT I), and energy metabolism (PPAR $\alpha)$ are involved in lipid metabolism. The obese mice induced by the HFD have association with abnormal lipid metabolism in the liver, including altered acetyl-CoA carboxylase 1 ( $A C C 1)$, fatty acid synthetase $(F A S)$, fasting-induced adipose factor $(F I A F)$, and $P P A R \gamma$ gene expression (Kang et al., 2013; Xin et al., 2014). In our study, HFD also induced abnormal lipid metabolism compared with 
mice fed a normal diet (data not shown), including the up-regulation of lipid synthesis genes and downregulation of lipolysis. For the HFD+B10 group, the mRNA expression of hepatic PPAR $\alpha$ and HMGCS2 is increased while DHCR24 mRNA expression decreases (Fig. 1). Thus, it could be deduced that the positive effect of B10 on lipid reduction may be due to the up-regulation of lipolysis and the downregulation of lipid synthesis. This is consistent with the study of Kang et al. (2013) and Park et al. (2013), in which the transcript level of PPAR $\alpha$ was also increased and the expression of some lipid synthesis and lipolysis genes was regulated by probiotics.

The abnormal lipid metabolism induced by high fat intake could also affect pro- and anti-oxidative balances in many tissues (Marczuk-Krynicka et al., 2009). The altered lipoprotein profiles enhance the synthesis and accumulation of intramyocellular TG, resulting in an increased synthesis of toxic fatty aciddelivered metabolites, causing enhanced lipid peroxides, hepatic membranes damage, and oxidative stress (Newsholme and Krause, 2014). Gao et al. (2011) demonstrated that HFD-fed ICR mice supplemented with lactic acid bacteria could enhance the activities of SOD and GSH-Px. In the present study, the GSH-Px activity was also significantly up-regulated in HFD+B10 group (Table 5). Moreover, the increased enzyme activity was accompanied by the regulation of genes related to antioxidant enzymes and oxidative stress. $\mathrm{XO}$ is an enzyme that catalyzes the oxidation of hypoxanthine to xanthine and could generate reactive oxygen species, leading to oxidative stress (Ardan et al., 2004). On the other hand, the p53, a tumor-suppressor protein, exhibits antioxidant activities to eliminate oxidative stress and ensure cell survival in response to low levels of oxidative stresses through the p53-regulated gene GPX1, manganese superoxide dismutase (MNSOD) or other pathways (Sablina et al., 2005; An et al., 2008; Liu and Xu, 2011; Chen et al., 2012; Wu et al., 2014). As we expected, the transcript level of $X O$ in mice treated with $\mathrm{B} 10$ being obviously down-regulated compared with HFD group, p53 expression is markedly up-regulated (Fig. 2). Moreover, as mentioned above, the activity of GPX was significantly increased (Table 5), which means, p53 may exert the antioxidant activity via the increment of GPX activity after B10 treatment. Our findings show that B10 has a positive regulatory effect on lipid profile, GSH-Px activity and $p 53, X O$ expression. All these alterations caused by $\mathrm{B} 10$ administration result in the attenuation of oxidative stress and DNA damage, which was verified by the decreased expression of antioxidantrelated genes (GR and $H s p 90)$ and lowered $8-\mathrm{OHdG}$ level, a major product of DNA oxidation (de SouzaPinto et al., 2001). Based on our study, the antioxidative activity of B10 is reflected in the increased activity of GSH-Px, the regulation of antioxidantrelated genes, like $X O$ and $p 53$ as well as the lipid profile and may be the modulation of gut microbiota. Accumulating evidences showed a strong correlation between gut microbiota and metabolic syndrome (Araya et al., 2002; Everard et al., 2014) and therefore, further research is needed to clarify the effect of $\mathrm{B} 10$ on the modulation of gut microbiota.

\section{Conclusions}

In conclusion, Bacillus subtilis B10 could decrease body weight gain of diet-induced obese mice by improving lipid metabolism and oxidative stress status.

\section{Acknowledgements}

We thank all workers of the study for their participation.

\section{Compliance with ethics guidelines}

Kai LEI, Ya-li LI, Yang WANG, Jing WEN, Hong-zhao WU, Dong-you YU, and Wei-fen LI declare that they have no conflict of interest.

All institutional and national guidelines for the care and use of laboratory animals were followed.

\section{References}

An, H.M., Park, S.Y., Lee, D.K., et al., 2011. Antiobesity and lipid-lowering effects of Bifidobacterium spp. in high fat diet-induced obese rats. Lipids Health Dis., 10:116. [doi:10.1186/1476-511X-10-116]

An, R., Tian, C., Shi, Q., et al., 2008. Overexpression of $\mathrm{nm} 23-\mathrm{H} 1$ in HeLa cells provides cells with higher resistance to oxidative stress possibly due to raising intracellular p53 and GPX1. Acta Pharmacol. Sin., 29(12): 1451-1458. [doi:10.1111/j.1745-7254.2008.00902.x]

Araya, M., Morelli, L., Reid, G., et al., 2002. Guidelines for the evaluation of probiotics in food. Report of a Joint $\mathrm{FAO} / \mathrm{WHO}$ working group on drafting guidelines for the evaluation of probiotics in food. London Ontario, Canada.

Ardan, T., Kovaceva, J., Cejkova, J., 2004. Comparative 
histochemical and immunohistochemical study on xanthine oxidoreductase/xanthine oxidase in mammalian corneal epithelium. Acta Histochem., 106(1):69-75. [doi:10.1016/ j.acthis.2003.08.001]

Charradi, K., Elkahoui, S., Limam, F., et al., 2013. High-fat diet induced an oxidative stress in white adipose tissue and disturbed plasma transition metals in rat: prevention by grape seed and skin extract. J. Physiol. Sci., 63(6): 445-455. [doi:10.1007/s12576-013-0283-6]

Chen, W., Jiang, T., Wang, H., et al., 2012. Does Nrf2 contribute to p53-mediated control of cell survival and death? Antioxid. Redox Signal., 17(12):1670-1675. [doi:10.1089/ ars.2012.4674]

de Souza-Pinto, N.C., Eide, L., Hogue, B.A., et al., 2001. Repair of 8-oxodeoxyguanosine lesions in mitochondrial DNA depends on the oxoguanine DNA glycosylase $(O G G l)$ gene and 8-oxoguanine accumulates in the mitochondrial DNA of OGG1-defective mice. Cancer Res., 61(14): 5378-5381.

Eckel, R.H., Grundy, S.M., Zimmet, P.Z., 2005. The metabolic syndrome. Lancet, 365(9468):1415-1428. [doi:10.1016/ S0140-6736(05)66378-7]

Endo, H., Niioka, M., Kobayashi, N., et al., 2013. Butyrateproducing probiotics reduce nonalcoholic fatty liver disease progression in rats: new insight into the probiotics for the gut-liver axis. PLoS ONE, 8(5):e63388. [doi:10. 1371/journal.pone.0063388]

Everard, A., Matamoros, S., Geurts, L., et al., 2014. Saccharomyces boulardii administration changes gut microbiota and reduces hepatic steatosis, low-grade inflammation, and fat mass in obese and type 2 diabetic $d b / d b$ mice. mBio, 5(3):e01011-e01014. [doi:10.1128/mBio.01011-14]

Furukawa, S., Fujita, T., Shimabukuro, M., et al., 2004. Increased oxidative stress in obesity and its impact on metabolic syndrome. J. Clin. Invest., 114(12):1752-1761. [doi:10.1172/JCI21625]

Gao, D., Zhu, G., Gao, Z., et al., 2011. Antioxidative and hypolipidemic effects of lactic acid bacteria from pickled Chinese cabbage. J. Med. Plants Res., 5(8):1439-1446.

Gorinstein, S., Leontowicz, H., Leontowicz, M., et al., 2006. Raw and boiled garlic enhances plasma antioxidant activity and improves plasma lipid metabolism in cholesterol-fed rats. Life Sci., 78(6):655-663. [doi:10.1016/j.1fs.2005.05. 069]

Hong, H.A., Duc, L.H., Cutting, S.M., 2005. The use of bacterial spore formers as probiotics. FEMS Microbiol. Rev., 29(4):813-835. [doi:10.1016/j.femsre.2004.12.001]

Hu, Y., Dun, Y., Li, S., et al., 2014. Effects of Bacillus subtilis $\mathrm{KN}-42$ on growth performance, diarrhea and faecal bacterial flora of weaned piglets. Asian Australas. J. Anim. Sci., 27(8):1131-1140. [doi:10.5713/ajas.2013.13737]

Jeong, S.K., Nam, H.S., Rhee, J.A., et al., 2004. Metabolic syndrome and ALT: a community study in adult Koreans. Int. J. Obes., 28(8):1033-1038. [doi:10.1038/sj.ijo.080 2698]

Kamata, H., Hirata, H., 1999. Redox regulation of cellular signalling. Cell. Signal., 11(1):1-14. [doi:10.1016/S08986568(98)00037-0]

Kang, J.H., Yun, S.I., Park, M.H., et al., 2013. Anti-obesity effect of Lactobacillus gasseri BNR17 in high-sucrose diet-induced obese mice. PLoS ONE, 8(1):e54617. [doi: 10.1371/journal.pone.0054617]

Li, Y.L., Lei, K., Xu, X., et al., 2013. Protective effect of Bacillus subtilis B10 against hydrogen peroxide-induced oxidative stress in a murine macrophage cell line. Int. J. Agric. Biol., 15(5):927-932.

Liu, D., Xu, Y., 2011. p53, oxidative stress, and aging. Antioxid. Redox Signal., 15(6):1669-1678. [doi:10.1089/ ars.2010.3644]

Marczuk-Krynicka, D., Hryniewiecki, T., Paluszak, J., et al., 2009. High fat content in diets and oxidative stress in livers of non-diabetic and diabetic rats. Polish J. Environ. Stud., 18(2):249-253.

Matsuda, M., Shimomura, I., 2013. Increased oxidative stress in obesity: implications for metabolic syndrome, diabetes, hypertension, dyslipidemia, atherosclerosis, and cancer. Obes. Res. Clin. Pract., 7(5):e330-e341. [doi:10.1016/j. orcp.2013.05.004]

Matsuzawa-Nagata, N., Takamura, T., Ando, H., et al., 2008. Increased oxidative stress precedes the onset of high-fat diet-induced insulin resistance and obesity. Metabolism, 57(8):1071-1077. [doi:10.1016/j.metabol.2008.03.010]

Newsholme, P., Krause, M., 2014. Diet, obesity, and reactive oxygen species - implications for diabetes and aging. In: Laher, I. (Ed.), Systems Biology of Free Radicals and Antioxidants. Springer Berlin Heidelberg, p.3361-3374. [doi:10.1007/978-3-642-30018-9_152]

Nikoskelainen, S., Ouwehand, A.C., Bylund, G., et al., 2003. Immune enhancement in rainbow trout (Oncorhynchus mykiss) by potential probiotic bacteria (Lactobacillus rhamnosus). Fish Shellfish Immunol., 15(5):443-452. [doi:10.1016/S1050-4648(03)00023-8]

Novak, R., Bogovič Matijašić, B., Terčič, D., et al., 2011. Effects of two probiotic additives containing Bacillus spores on carcass characteristics, blood lipids and cecal volatile fatty acids in meat type chickens. J. Anim. Physiol. Anim. Nutr. (Berl.), 95(4):424-433. [doi:10.1111/j.14390396.2010.01068.x]

Panda, A.K., Rao, S.V.R., Raju, M.V., et al., 2006. Dietary supplementation of Lactobacillus sporogenes on performance and serum biochemico-lipid profile of broiler chickens. J. Poult. Sci., 43(3):235-240. [doi:10.2141/jpsa. 43.235]

Park, D.Y., Ahn, Y.T., Park, S.H., et al., 2013. Supplementation of Lactobacillus curvatus HY7601 and Lactobacillus plantarum KY1032 in diet-induced obese mice is associated with gut microbial changes and reduction in obesity. PLoS ONE, 8(3):e59470. [doi:10.1371/journal.pone. 0059470]

Rafter, J., 2002. Lactic acid bacteria and cancer. Br. J. Nutr., 88(S1):S89-S94. [doi:10.1079/BJN2002633]

Rizvi, F., Iftikhar, M., George, J.P., 2003. Beneficial effects of 
fish liver preparations of sea bass (Lates calcarifer) versus gemfibrozil in high fat diet-induced lipid-intolerant rats. J. Med. Food, 6(2):123-128. [doi:10.1089/10966200 3322233521]

Sablina, A.A., Budanov, A.V., Ilyinskaya, G.V., et al., 2005. The antioxidant function of the $\mathrm{p} 53$ tumor suppressor. Nat. Med., 11(12):1306-1313. [doi:10.1038/nm1320]

Sies, H., 1997. Oxidative stress: oxidants and antioxidants. Exp. Physiol., 82(2):291-295. [doi:10.1113/expphysiol. 1997.sp004024]

Tsai, Y.T., Cheng, P.C., Pan, T.M., 2014. Anti-obesity effects of gut microbiota are associated with lactic acid bacteria. Appl. Microbiol. Biotechnol., 98(1):1-10. [doi:10.1007/ s00253-013-5346-3]

Valko, M., Rhodes, C.J., Moncol, J., et al., 2006. Free radicals, metals and antioxidants in oxidative stress-induced cancer. Chem. Biol. Interact., 160(1):1-40. [doi:10.1016/j.cbi 2005.12.009]

Wang, J., Tang, H., Zhang, C., et al., 2015. Modulation of gut microbiota during probiotic-mediated attenuation of metabolic syndrome in high fat diet-fed mice. ISME J., 9: 1-15. [doi:10.1038/ismej.2014.99]

Westerbacka, J., Corner, A., Tiikkainen, M., et al., 2004. Women and men have similar amounts of liver and intraabdominal fat, despite more subcutaneous fat in women: implications for sex differences in markers of cardiovascular risk. Diabetologia, 47(8):1360-1369. [doi:10. 1007/s00125-004-1460-1]

Wu, R.M., Sun, Y.Y., Zhou, T.T., et al., 2014. Arctigenin enhances swimming endurance of sedentary rats partially by regulation of antioxidant pathways. Acta Pharmacol. Sin., 35(10):1274-1284. [doi:10.1038/aps.2014.70]

Xin, J., Zeng, D., Wang, H., et al., 2014. Preventing non-alcoholic fatty liver disease through Lactobacillus johnsonii BS15 by attenuating inflammation and mitochondrial injury and improving gut environment in obese mice. Appl. Microbiol. Biotechnol., 98(15):6817-6829. [doi:10.1007/s00253-014-5752-1]

\section{List of electronic supplementary materials}

Table S1 Compositions of mice normal diet

Data S1 Methods for biochemical parameter detection

\section{中文概要}

题 目: 日粮中添加枯草芽狍杆菌 B10 对高脂日粮诱导的 小鼠脂肪代谢及抗氧化的影响

目 的: 探究枯草芽孢杆菌 B10 对高脂日粮诱导的小鼠脂 肪代谢及氧化应激的改善作用, 并初步探讨其作 用机制。

创新点: 证明了枯草芽孢杆菌 B10 可以有效改善高脂日粮 诱导的小鼠脂肪代谢和氧化应激, 且发现此作用 主要与 $\mathrm{B} 10$ 调节脂肪代谢基因（PPAR $\alpha$ 、 $D H C R 24 、 H M G C S 2)$ 及氧化应激基因（XO、p53） 表达和谷胱甘肽过氧化物酶 (GSH-Px)活力有关。

方 法: 将 ICR 雄鼠分为对照组 (饲喂高脂日粮) 和实验 组（饲喂添加枯草芽孢杆菌菌粉的高脂日粮）。 饲喂 30 天后, 收集小鼠的血清及肝脏样品。采 用试剂盒测定抗氧化及脂肪代谢相关指标和肝 脏中 8 -差基脱氧鸟苷 (8-OHdG) 含量。使用苂 光定量聚合酶链式反应 (PCR) 测定小鼠肝脏中 脂肪代谢和氧化应激相关基因的表达水平。

结 论: 饲喂含有枯草芽狍杆菌 B10 的高脂日粮能够有效 降低小鼠的体重（表 2), 降低血清中葡萄糖和 甘油三酯含量及谷草转氨酶和谷丙转氨酶活力 （表 3 和 4）; 下调肝脏中脂肪合成相关基因表 达量, 但上调脂肪分解相关基因表达量 (图 1), 并提高肝脏中抗氧化相关基因表达量（图 2）。 综上所述, 枯草芽孢杆菌 B10 能有效调节小鼠脂 肪代谢, 并改善其氧化应激。

关键词: 枯草芽孢杆菌; 高脂日粮; 氧化应激; 脂肪代谢 